\title{
O DELEGACIONISMO NO STF: \\ UMA TréPlica a Virgílio AFONSO da Silva
}

\author{
DANILO DOS SANTOS ALMEIDA ${ }^{\dagger}$ \\ ANDRE MARTINS BOGOSSIAN ${ }^{\dagger \dagger}$
}

RESUMO: No presente artigo, pretendemos responder às críticas elaboradas por Virgílio Afonso da Silva, em O Relator dá voz ao STF? Uma réplica a Almeida e Bogossian, ao nosso artigo "Nos termos do voto do Relator": considerações acerca da fundamentação coletiva nos acórdãos do STF. Nosso propósito com o presente artigo é duplo. Além de responder às críticas que nos dirigiu nosso interlocutor, pretendemos apresentar com mais clareza o argumento sugerido em nosso artigo anterior (que chamamos de argumento do delegacionismo), definindo as condições para sua afirmação, e situá-lo no pano de fundo de nossa pesquisa, a respeito da natureza coletiva dos julgamentos no STF - mais especificamente, a busca por critérios para atribuir determinados fundamentos de decisão à corte, entendida enquanto grupo-agente. Concluímos que, apesar de algumas críticas de Silva serem pertinentes, elas não comprometem decisivamente nossa tese central, de modo que ainda consideramos haver boas evidências para pensar que a autocompreensão da corte expressa em seus acórdãos confirma a hipótese de que a corte remete suas razões de decidir para o voto do relator do acórdão.

PAlAVRAS-ChAVE: Supremo Tribunal Federal; Julgamentos de Grupo; Interpretação Jurídica; Deliberação; Precedentes.

\footnotetext{
${ }^{\dagger}$ Professor da Escola Superior de Criciúma (ESUCRI), Doutor em Direito Constitucional e Teoria do Estado pela PUC-Rio, Mestre em Filosofia e Teoria do Direito e Bacharel em Direito pela Universidade Federal de Santa Catarina (UFSC). ${ }^{\dagger}$ Mestre em Direito pela Harvard Law School e em Teoria do Estado e Direito Constitucional pela Pontifícia Universidade Católica do Rio de Janeiro (PUC-Rio), Bacharel pela Faculdade Nacional de Direito da Universidade Federal do Rio de Janeiro (UFRJ) e Pesquisador da Escola de Direito da Fundação Getulio Vargas do Rio de Janeiro (FGV Direito Rio).
} 


\begin{abstract}
In this paper, we intend to answer the criticisms made by Virgílio Afonso da Silva in "Does the Rapporteur give voice to the Supreme Court? A reply to Almeida and Bogossian" to our paper "In the terms of the Rapporteur's opinion". Our purpose with this article is twofold. Besides responding to the criticisms addressed to us by our interlocutor, we intend to present more clearly the argument suggested in our previous article (which we call the delegationist argument), specifying the conditions for its validity, and placing it in the context of our broader research project, regarding the collective nature of the STF judgements - more specifically, the search for criteria to assign the court, understood as group agents, rationales. We suggest that although some of Silva's criticisms are correct, they do not decidedly compromise our main argument, so that we still think that evidence shows that the delegation thesis still stands as valid.
\end{abstract}

KEYWORDS: Brazilian Supreme Court; Group Judgment; Legal Interpretation; Deliberation; Precedents. 
SUMÁRIO:

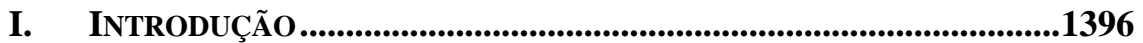

II. RESUMO DO DEBATE ....................................................................1398

III. O ARGUMENTO DELEGACIONISTA..............................................1400

IV. RESPOSTAS ÀS CRITICAS...................................................................1405

1. Deliberativismo como premissa nas entrevistas.................1406

2. Ano de 2004 como ponto de inflexão

( $1^{\mathrm{a}}$ condição do delegacionismo) ..............................................1407

3. Significado da expressão

( $2^{\mathrm{a}}$ condição do delegacionismo) ..............................................1414

4. Quantas cortes cabem no STF?

A importância da distinção entre casos

mais ou menos importantes no STF.

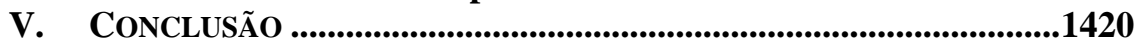

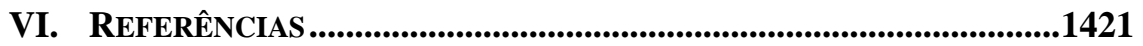

\section{TABLE OF CONTENTS:}

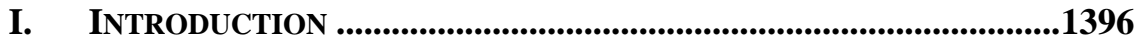

II. SUMARY OF THE DEBATE .....................................................................1398

III. THE DELEGATION THESIS ........................................................................1400

IV. RESPONSES TO THE CRITICS.........................................................1405

1. Deliberation thesis as a premiss on the interviews.............1406

2. The year of 2004 as a point of inflection

(1st condition of the delegation thesis) ...................................1407

3. The meaning of the expression

( $2^{\mathrm{a}}$ condition of the delegation thesis) ....................................1414

4. How many courts fit in the Supreme Federal Court?

The importance of the distinction between cases

more or less important in the Supreme Court...................1417

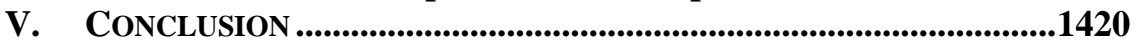

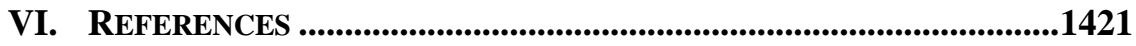




\section{INTRODUÇÃO}

O presente artigo é mais um lance em um saudável debate que travamos nesta Revista Estudos Institucionais com Virgílio Afonso da Silva sobre o papel do relator na deliberação no Supremo Tribunal Federal. Esse debate nasceu de nosso artigo "Nos Termos do Voto do Relator": considerações acerca da fundamentação coletiva nos acórdãos do STF", que utilizou material de obra anterior de $S_{i l v a}^{2}$ e que foi objeto das considerações de Silva em O Relator dá voz ao STF? Uma réplica a Almeida e Bogossian. ${ }^{3}$

Nosso propósito com o presente artigo é duplo. Por um lado, pretendemos responder às críticas que nos dirigiu nosso interlocutor. Por outro, pretendemos apresentar com mais clareza o argumento sugerido em nosso artigo anterior (que chamamos de argumento do delegacionismo) e situá-lo no pano de fundo de nossa pesquisa, a respeito da coletividade das razões de decidir do STF - mais especificamente a busca por critérios para atribuir determinada decisão à corte ou a determinado ministro ou ministros individualmente. ${ }^{4}$

Como afirmamos na oportunidade, aquele artigo foi o primeiro dentre uma série de trabalhos ${ }^{5}$ em que refletimos sobre a natureza coletiva do

${ }^{1}$ ALMEIDA, Danilo dos Santos; BOGOSSIAN, Andre Martins. “Nos Termos do Voto do Relator": Considerações acerca da Fundamentação Coletiva nos Acórdãos do STF.

Revista Estudos Institucionais, Vol. 2, 1, 2016.

2 SILVA, Virgílio. "Um Voto Qualquer"? O papel do ministro relator na deliberação no Supremo Tribunal Federal. Revista Estudos Institucionais, Vol. 1, 1, 2015.

${ }^{3}$ SILVA, Virgílio. O Relator dá Voz ao STF? Uma réplica a Almeida e Bogossian.

Revista Estudos Institucionais, Vol. 2, 2, 2016.

${ }^{4}$ ALMEIDA, Danilo dos Santos. As Razões Ocultas do Supremo Tribunal Federal: um estudo sobre agenciamento de grupo na Corte. Tese (Doutorado em Teoria do Estado e Direito Constitucional), Pontifícia Universidade Católica do Rio de Janeiro, Rio de Janeiro, RJ, 2016.

${ }^{5}$ Alguns já publicados: ALMEIDA, Danilo dos Santos. As Razões Ocultas do Supremo Tribunal Federal: um estudo sobre agenciamento de grupo na Corte. Tese (Doutorado em Teoria do Estado e Direito Constitucional), Pontifícia Universidade Católica do Rio de Janeiro, Rio de Janeiro, RJ, 2016; ALMEIDA, Danilo dos Santos; BOGOSSIAN, Andre Martins. "Nos Termos do Voto do Relator": Considerações acerca da Fundamentação Coletiva nos Acórdãos do STF. Revista Estudos Institucionais, Vol. 2, 1, 2016; ALMEIDA, Danilo dos Santos. A Fundamentação de Decisões Judiciais Colegiadas e o Problema de sua Demarcação. In: Daniel Marchiori Neto; Danilo dos Santos Almeida (Orgs.). Estudos em Filosofia do Direito, Volume II: Ensaios em 
STF e sua capacidade, enquanto ente distinto do conjunto de seus membros, de ser o autor de decisões. Nosso interesse mais amplo é a busca por critérios de delimitação das manifestações coletivas do STF, contra as manifestações individuais de seus membros. ${ }^{6}$

Este trabalho começa com uma breve recapitulação do debate no primeiro tópico. Logo em seguida, segue para uma apresentação mais detalhada do argumento delegacionista. Cada uma das subdivisões desta seção expõe um dos componentes do argumento, além de algumas de suas implicações e características. Já a seção seguinte procura efetivamente tratar da tréplica a Virgílio Afonso da Silva. Tentaremos responder as questões levantadas por nosso interlocutor na ordem em que ele as apresenta:

Para tanto, este artigo é dividido em 5 tópicos. O primeiro deles dedica-se a uma questão metodológica preliminar, relativa a um suposto "viés deliberativista" das entrevistas que fiz com os ministros do STF. O segundo tópico pretende apontar alguns problemas nos dados utilizados na pesquisa de Almeida e Bogossian, especialmente para mostrar que o uso da expressão "nos termos do voto do relator", mesmo antes de 2005, era mais frequente do que eles supunham. Independente de possíveis imprecisões nos dados, o terceiro tópico ocupa-se das possíveis interpretações para a expressão "nos termos do voto do relator". O tópico seguinte aborda o debate sobre a diferenciação entre casos importantes e casos corriqueiros e procura demonstrar, de forma muito breve, que ela é central para a compreensão do processo deliberativo e decisório do STF. O último tópico é dedicado à conclusão do artigo. ${ }^{7}$

Assim sendo, a quarta seção se inicia com uma tentativa de esclarecer o que quisemos dizer quando alegamos haver uma premissa deliberativista presente na obra de Silva, que utilizamos como base para nossa primeira incursão no tema. Em seguida, tratamos das críticas metodológicas de Silva à nossa pesquisa nos bancos de jurisprudência,

Filosofia do Direito. Rio Grande, RS: Editora FURG, 2017; BOGOSSIAN, Andre Martins; e ALMEIDA, Danilo dos Santos. É Possível Falar em Precedente “do Supremo"? In: Joaquim Falcão; Diego Werneck Arguelhes; Felipe Recondo (Orgs.).

Onze Supremos: o Supremo em 2016. Belo Horizonte, MG: Letramento, 2017.

${ }^{6}$ ALMEIDA, Danilo dos Santos; BOGOSSIAN, Andre Martins. "Nos Termos do Voto do Relator": Considerações acerca da Fundamentação Coletiva nos Acórdãos do STF. Revista Estudos Institucionais, Vol. 2, 1, 2016, p. 266.

7 SILVA, Virgílio. O Relator dá Voz ao STF? Uma réplica a Almeida e Bogossian.

Revista Estudos Institucionais, Vol. 2, 2, 2016, p. 651. 
que nos levaram à descoberta de um curioso fenômeno no processo deliberativo do STF: A prática, que subitamente se tornou dominante no ano de 2004, no uso da expressão "nos termos do voto do Relator" nos acórdãos da corte. Continuamos a quarta seção respondendo às críticas relativas ao significado de tal expressão quando utilizada pelos Ministros no âmbito da decisão de um caso no STF. Fechamos a seção pretendendo mostrar como o argumento delegacionista sobrevive à crítica feita por Silva de que ele prejudicaria o processo deliberativo nos que ele denomina de casos mais difíceis ou importantes. Por fim, na quinta seção apresentamos nossas conclusões, reiterando a validade do argumento delegacionista apesar da pertinência de algumas críticas de Silva.

\section{RESUMO DO DEBATE}

Virgílio Afonso da Silva publicou um instigante artigo na primeira edição da presente revista relatando uma série de entrevistas com ministros e ex-ministros do Supremo sobre sua percepção de aspectos destacados da prática deliberativa da corte, em especial a respeito do papel do relator no processo deliberativo. Ele muito acertadamente destaca que, curiosamente, apesar de estarem presentes em grande parte das cortes supremas e tribunais constitucionais ao redor do mundo, a figura do relator ainda é pouco estudada. Ele afirma: "pouco se sabe para usar o título de um dos poucos artigos especificamente dedicados ao tema - se o juiz relator é 'o senhor do processo ou apenas um dentre oito'" ${ }^{8}$ É justo dizer que, no que se refere ao STF, o autor teme que o segundo cenário seja verdadeiro. Ao menos suas entrevistas com os ministros do STF parecem indicar que essa é uma ideia subjacente à prática deliberativa do tribunal. E como não parece ter havido mudanças significativas na prática deliberativa do STF há décadas, as regras decisórias não refletem as perspectivas individuais dos ministros, mas uma prática institucionalizada, entrincheirada.

Ao analisar como os ministros percebem o papel do relator, Silva afirma estar interessado não nos casos corriqueiros, mas nos ditos casos mais importantes. Uma das hipóteses de Silva diz respeito ao trabalho do relator aí:

Na medida em que nesses casos - ao contrário do que ocorre normalmente -

8 SILVA, Virgílio. “Um Voto Qualquer"? O papel do ministro relator na deliberação no Supremo Tribunal Federal. Revista Estudos Institucionais, Vol. 1, 1, 2015, p. 183. 
todos os ministros costumam levar seus votos prontos para a sessão de julgamento, é possível supor que o papel e o grau de influência do relator sejam diferentes se comparados com o cenário usual em que os demais ministros chegam à sessão de julgamento com informações muito superficiais sobre o que vai ser julgado (grifo nosso). ${ }^{9}$

Em resposta, defendemos uma visão diferente..$^{10}$ Não que o relator seja senhor do processo, mas parece que ele deve ser visto como uma espécie de preposto da corte para alguns temas. Há uma regra tácita do processo deliberativo da corte segundo a qual a corte coletivamente delega ao relator o deve de fundamentar suas decisões. Podemos explicar essa posição - que batizamos de delegacionismo - da seguinte forma: o Supremo $^{11}$ tem uma incapacidade estrutural de produzir razões institucionais para suas decisões; e o mecanismo que ele utiliza para lidar com essa dificuldade é a adoção dos fundamentos do voto do relator do acórdão como fundamentos para o próprio acórdão. Mais precisamente, para o delegacionismo, a corte endossa a posteriori as razões previamente apresentadas pelo ministro que veio a se tornar o relator do acórdão - que nem sempre é o relator original do caso.

Silva publicou, na edição seguinte da Revista de Estudos Institucionais, uma cuidadosa resposta ao nosso artigo. ${ }^{12}$ Silva é caridoso em sua interpretação e generoso em seus comentários. Mais importante, oferece contribuições inestimáveis para o programa de pesquisa que estamos tentando propor. Torcemos para que esse seja apenas o início de um proveitoso debate acadêmico. Nossas discordâncias talvez sejam menos profundas do que pareçam. Apresentamos a posição delegacionista não propriamente como uma posição a ser endossada - nós mesmos não estamos convencidos de que essa é a melhor chave de leitura do Supremo

${ }_{9}$ SILVA, Virgílio. “Um Voto Qualquer"? O papel do ministro relator na deliberação no Supremo Tribunal Federal. Revista Estudos Institucionais, Vol. 1, 1, 2015, p. 184.

${ }^{10}$ ALMEIDA, Danilo dos Santos; BOGOSSIAN, Andre Martins. "Nos Termos do Voto do Relator": Considerações acerca da Fundamentação Coletiva nos Acórdãos do STF.

Revista Estudos Institucionais, Vol. 2, 1, 2016.

${ }^{11}$ É provável que o delegacionismo se aplique às outras cortes nacionais, porém nos dedicamos a essa especificamente. No artigo anterior, coletamos alguns dados referentes ao processo decisório do STJ que corroboram essa hipótese. ALMEIDA, Danilo dos Santos; BOGOSSIAN, Andre Martins. "Nos Termos do Voto do Relator": Considerações acerca da Fundamentação Coletiva nos Acórdãos do STF. Revista Estudos Institucionais, Vol. 2, 1, 2016. 12 SILVA, Virgílio. O Relator dá Voz ao STF? Uma réplica a Almeida e Bogossian. Revista Estudos Institucionais, Vol. 2, 2, 2016. 
em termos práticos, quando comparada com as outras possibilidades aventadas em nosso trabalho original, o negacionismo e o agregativismo.

Procuramos chamar atenção para o fato de que, por ignorar completamente considerações sobre a noção de agenciamento de grupo, o debate acadêmico nacional sobre o processo decisório na corte gera insuficiências importantes. A busca pelos posicionamentos oficiais da corte se perde entre os debates sobre colegialidade, consenso e deliberação racional, enquanto as questões estruturais - regras constitutivas e procedimentais - sobre a formação das decisões coletivas acabam ficando relegadas. A proposta de compreensão das decisões do Supremo a partir do delegacionismo aponta para um desses elementos estruturais que precisa ser levado em conta.

Passamos, então, a esclarecer o que é a tese ou argumento delegacionista e quais as condições necessárias para sua verificação.

\section{O ARGUMENTO DELEGACIONISTA}

A seguir, vamos apresentar uma breve explicação de como pretendemos sustentar que talvez a ratio deciendi seja aquilo que o relator do acórdão tiver escrito como a fundamentação do seu voto individual. O delegacionismo é uma tentativa de resolver um problema que aflige a parte do acórdão que descreve sua fundamentação coletiva: o STF não explicita com clareza quais critérios adota para formar uma posição sobre os fundamentos de seus acórdãos. Em outro artigo, um de nós definiu o chamado problema da demarcação como "a incerteza quanto à abrangência do conjunto de atitudes atribuíveis à corte coletivamente, decorrente da falta de apresentação clara do critério de aceitação conjunta adotado pelos membros". ${ }^{13}$

Em síntese, a questão é que a fundamentação de decisões coletivas é um tipo muito peculiar de proposição. Por um lado, ela precisa guardar relação lógica e argumentativa com o dispositivo da decisão, já que ela serve justamente para sustentá-lo persuasivamente. Por outro, os membros podem sustentar uma mesma solução para um caso por

${ }^{13}$ ALMEIDA, Danilo dos Santos. A Fundamentação de Decisões Judiciais Colegiadas e o Problema de sua Demarcação. In: Daniel Marchiori Neto; Danilo dos Santos Almeida (Orgs.). Estudos em Filosofia do Direito, Volume II: Ensaios em Filosofia do Direito. Rio Grande, RS: Editora FURG, 2017, p. 34. 
diferentes razões, causando uma situação de dispersão de fundamentos. ${ }^{14}$ É possível, por exemplo, que todos os membros concordem majoritariamente sobre um resultado, mas que nenhuma das razões que podem razoavelmente sustentar esse resultado consiga o apoio da maioria. Encontramos uma drástica manifestação do problema da demarcação para identificar a fundamentação coletiva quando a corte não diz exatamente como resolver situações desse tipo.

O STF parece, à primeira vista, não oferecer critérios claros para a identificação dos fundamentos coletivos e, assim, sujeitar os leitores de seus acórdãos ao problema da demarcação. Contudo, o que o argumento delegacionista pretende sustentar é que a corte oferece sim tal critério, e de forma bastante explícita. Vemos na quase totalidade dos acórdãos recentes que as decisões foram tomadas "nos termos do voto do relator". $\mathrm{O}$ delegacionismo leva essa expressão a sério. No artigo anterior, definimos delegacionismo como a hipótese segundo a qual "a fundamentação da corte é idêntica à fundamentação do voto do relator do acórdão". ${ }^{15}$ Podemos apresentar o argumento delegacionista mais rigorosamente da seguinte forma: dada a ocorrência de três condições específicas, devemos atribuir ao STF a intenção de endossar as razões apresentadas pelo relator do acórdão em seu voto; consequentemente, satisfeitas as condições, essas razões do relator equivalem à fundamentação do acórdão.

As condições são as seguintes: i) que a ausência de uma opinion of the court - um texto redigido após o julgamento que explicite as razões da corte para a decisão tomada - seja sistemática; ii) que o uso da expressão "nos termos do voto do relator" no campo "decisão" do acórdão, seja uma prática habitual e previsível; e iii) que a expressão, quando usada nesse contexto, signifique que a corte adota, como fundamento de sua decisão, as razões oferecidas pelo relator do acórdão em seu próprio voto. Sigamos agora para a explicação de cada uma das condições.

A primeira condição, a inexistência de uma "opinion of the court", não é particularmente controversa. Podemos afirmar que decisões deliberativas podem, em geral, ser expressas como se fossem a

${ }^{14}$ Sobre o problema da dispersão de fundamentos, ver LEITE, Fábio Carvalho;

BRANDO, Marcelo Santini. Dispersão de Fundamentos no Supremo Tribunal Federal.

Direito, Estado e Sociedade, No. 48, 2016; ALMEIDA, Danilo. Estudos em Filosofia

do Direito - Volume II: ensaios em filosofia do direito. Rio Grande: FURG, 2017, pp. 51 e 52 .

${ }^{15}$ ALMEIDA, Danilo dos Santos; BOGOSSIAN, Andre Martins. "Nos Termos do Voto do Relator": Considerações acerca da Fundamentação Coletiva nos Acórdãos do STF.

Revista Estudos Institucionais, Vol. 2, 1, 2016, p. 290. 
manifestação de uma única entidade ou como a manifestação dos múltiplos membros dessa entidade. Chama-se seriatim o primeiro tipo de decisão e per curiam, o segundo. O STF é uma corte seriatim..$^{16}$ Isso significa justamente que, em seu processo decisório, não há uma etapa posterior ao julgamento em que um ministro, em nome de toda a corte, anuncie o resultado, enunciando as razões que os ministros coletivamente aceitam como fundamentos para a decisão.

A segunda condição é a existência de uma regra tácita ou um hábito de uso da expressão "nos termos do voto do relator" nos acórdãos, ou seja, após o julgamento. Essa condição é central para o delegacionismo, já que um julgamento de grupo é sempre produto dos arranjos internos que organizam e coordenam as ações coletivas dos membros. No artigo anterior $^{17}$, argumentamos que expressões de juízos coletivos - como é o caso dos fundamentos de uma decisão judicial - são o produto da ação coordenada dos membros de um grupo. Essa coordenação se dá de acordo com regras e hábitos internos do grupo, que podem ser explícitos ou implícitos. É o respeito a essas regras e hábitos - que são compartilhados e respeitados por todos os membros relevantes do grupo - que permitem que tratemos conjuntos de ações individuais como ações de grupo. Podemos dizer que tais regras e hábitos constituem a capacidade de agenciamento do grupo, amalgamando ações. No caso do STF, as regras explícitas de comportamento são bem conhecidas; naturalmente, já que se trata da corte brasileira mais importante. O que é surpreendente é que haja pouca discussão sobre as regras e hábitos implícitos. Adiante, iremos apresentar mais dados empíricos sobre o

${ }^{16}$ MENDES, Conrado. Projeto de uma Corte Deliberativa. In: Adriana Vojvodic, et. al.. (Orgs.). Jurisdição Constitucional no Brasil. São Paulo, SP: Malheiros, 2012, p. 65. Há que se notar que a verdade do delegacionismo faria com que o STF fosse um tipo muito peculiar de corte seriatim. A corte não redigiria uma decisão fundamentada, mas haveria uma decisão fundamentada integralmente atribuível à corte. Cf. ALMEIDA, Danilo dos Santos; BOGOSSIAN, Andre Martins. "Nos Termos do Voto do Relator": Considerações acerca da Fundamentação Coletiva nos Acórdãos do STF. Revista Estudos Institucionais, Vol. 2, 1, 2016, p. 293-294, nota no 69.

17 ALMEIDA, Danilo dos Santos; BOGOSSIAN, Andre Martins. "Nos Termos do Voto do Relator": Considerações acerca da Fundamentação Coletiva nos Acórdãos do STF. Revista Estudos Institucionais, Vol. 2, 1, 2016, p. 273-276. Ver também ALMEIDA, Danilo dos Santos. A Fundamentação de Decisões Judiciais Colegiadas e o Problema de sua Demarcação. In: Daniel Marchiori Neto; Danilo dos Santos Almeida (Orgs.). Estudos em Filosofia do Direito, Volume II: Ensaios em Filosofia do Direito. Rio Grande, RS: Editora FURG, 2017, p. 38-43. 
funcionamento da corte.

A diferença entre uma simples prática coincidente entre os membros e um hábito constitutivo do agenciamento da corte é central. Para que o uso da fórmula seja significativo, ele precisa ser um exemplo de hábito constitutivo. Nas palavras de Tuomela, ele deve ser parte do ethos do grupo, do conjunto de suas propriedades, práticas e regras, constitutivas. $^{18}$ No trabalho anterior, argumentamos que o uso da fórmula é um elemento central por causa de seu conteúdo e da sua alta frequência. Quanto ao conteúdo, podemos dar diferentes interpretações ao significado da expressão, mas se a lemos em seu sentido mais literal, ela parece expressar um endosso oficial da corte das razões oferecidas pelo relator. Quanto à frequência, ela parece indicar que algo além de uma escolha pessoal de cada ministro-relator ao produzir a ementa. Usando a fórmula, ele está fazendo algo que pode ser esperado por qualquer pessoa que conheça a prática decisória do STF nas últimas duas décadas. Isso significa que ele não está tomando uma decisão pessoal, mas está fazendo algo que se deve razoavelmente esperar de qualquer relator de acórdão.

Este último ponto convém repetir para que fique claro. Para a posição delegacionista, em um dado acórdão, não é o seu relator que impõe suas razões como as razões da corte. Não poderia ser diferente, já que todo julgamento e crença atribuídos à corte precisam ser coletivos em um sentido forte - ou seja, precisam ser uma etapa de um plano de ação do grupo, compartilhado e aceito por todos os seus membros. ${ }^{19} \mathrm{Se}$, por exemplo, escrever "nos termos do voto do relator" como forma de explicitar os fundamentos coletivos da corte fosse uma prática de um ministro específico, então o delegacionista trataria essas palavras como expressão da vontade individual de um ministro mal-intencionado ou rebelde. $\mathrm{O}$ que indica a delegação não é a expressão individual dos relatores, mas o fato de que o uso da expressão constitui regra.

Uma consequência curiosa dessa posição é que, uma vez reconhecida

${ }^{18}$ TUOMELA, Raimo. Social Ontology: collective intentionality and group agents. New York, NY: Oxford University Press, 2013, p. 26.

${ }^{19}$ Segundo Tuomela, a noção de julgamentos coletivos em um sentido forte é útil para distinguir entre os vários sentidos que "coletivo" pode conter. Um julgamento coletivo, por exemplo, pode ser uma atitude proposicional que vários indivíduos que não estão relacionados de qualquer outra maneira compartilha. O que caracteriza o julgamento coletivo em sentido forte é o contexto estabelecido pelas práticas institucionais do grupo, segundo o qual as ações dos membros devem ser interpretadas. TUOMELA, Raimo. Social Ontology: collective intentionality and group agents. New York, NY: Oxford University Press, 2013, p. 63. 
a existência do hábito, o comportamento deve ser tratado como desviante. Se usar a expressão "nos termos do voto do relator" nas ementas é um hábito constitutivo dos fundamentos de decidir da corte, então rebelde é o ministro que não faz uso dessa expressão. Ele está contrariando um elemento constitutivo do processo decisório da corte. A conclusão é que há delegação mesmo quando a expressão não é utilizada. A decisão coletiva da corte de, nas últimas duas décadas, incluir o uso da expressão em quase $98 \%$ das ementas de seus acórdãos fez com que a delegação se tornasse um elemento tácito relevante em todas as etapas do processo decisório. Mesmo nas raríssimas vezes em que a expressão não aparece, a expectativa de seu uso já produziu seus efeitos ao longo do processo deliberativo. É isso que sustenta o delegacionismo.

Um equívoco compreensível seria atribuir ao delegacionismo a pretensão de descrever apenas casos em que a fórmula tenha sido efetivamente utilizada, mas esse não é o caso. O delegacionismo pretende-se categórico. Isso é importante porque a natureza coletiva da Supremo exige que qualquer manifestação legitimamente atribuível a esse órgão seja aceitável coletivamente por todos os membros. Um ministro, ainda que seja o relator, não pode, movido apenas pela própria vontade, falar em nome da corte. Ele precisa de um mandato do órgão coletivo que representa.

O delegacionismo pretende sustentar que o relator tem esse mandato; e a evidência para isso é a predominância do uso da expressão na prática recente da corte. Se ela for usada em suficientes casos, podemos afirmar com segurança que todo ministro está ciente que ela estará inscrita em todos os acórdãos de que participar. É claro que é difícil precisar o que significa "suficientes casos". Felizmente para o delegacionista, a quantidade relativa de casos é de fato tão grande que afasta qualquer dúvida razoável nesse sentido.

Concluindo, o objetivo não é apenas caracterizar a expressão "nos termos do voto do relator" como uma instrução para leitores dos acórdãos. Mais do que isso, o objetivo é caracterizar o uso da expressão como elemento estável do processo decisório e, como tal, um dos componentes que condicionam o resultado da decisão coletiva; um dos componentes do ethos do Supremo.

A terceira e última condição diz respeito ao significado da expressão. Uma vez verificado que a prática institucional de se afirmar que a decisão da corte é tomada "nos termos do voto do relator", é importante descobrir o que exatamente essa expressão significa. Para que o delegacionismo seja verdadeiro, ela deve significar que o fundamento recomendado pelo relator em seu voto está sendo adotados pela corte como fundamentos para a decisão final. 
Literalmente, a expressão parece afirmar justamente isso. É difícil imaginar o que "termos do voto" significa senão o conteúdo dos votos, que são redigidos individualmente. Assim, assumiremos que não existe uma alternativa para o significado dessa expressão. Uma outra possibilidade, contudo, é que a expressão não tenha qualquer significado relevante. Esse será o caso se, ao inclui-la no acórdão, o relator não quiser dizer nada com ela. Por isso, a defesa do delegacionismo passa por sustentar que essa expressão tão recorrente em acórdãos recentes não é vazia; que, ao contrário, deve ser lida como uma asserção de seu significado literal.

Uma consequência importante do argumento deve ser nos alertar para a importância da noção de agenciamento de grupo na prática jurídica. Enquanto esse problema tem sido debatido em outros lugares há décadas ${ }^{20}$, ele continua sendo amplamente negligenciado no Brasil. Mais do que qualquer propósito prático, o problema da demarcação e a solução delegacionista devem nos orientar para a forma de avaliação crítica que devemos fazer do processo decisório das cortes brasileiras. Os fundamentos decisórios no processo nos tribunais não são aqueles que melhor justifiquem a decisão; os fundamentos são sempre o que os membros decidem que é, seguindo as regras e práticas constitutivas do processo decisório, ainda que sejam fracos ou incoerentes. Que a hipótese do delegacionismo seja, ao mesmo tempo, estranha e viável serve para mostrar que há algo de fundamental no direito que tem passado sob o radar do pensamento jurídico nacional. Assim, uma das consequências mais importantes do argumento delegacionista é chamar a atenção para o tema do agenciamento de grupos nas cortes.

\section{RESPOSTAS Às CRITICAS}

A primeira enunciação do delegacionismo foi publicada no contexto da crítica de uma posição de Virgílio Afonso da Silva, o que provocou sua resposta, com valiosas críticas ao nosso trabalho. Passamos a abordá-las agora.

${ }^{20}$ Por exemplo, Kornhauser e Sager escrevem, há três décadas: “Appellate adjudication, the common, almost exclusive focus of theories of adjudication, is thus essentially a group process, yet extant theories neither explain the group nature of the process nor take it into account". KORNHAUSER, Lewis; SAGER, Lawrence. Unpacking the Court. The Yale Law Journal, Vol. 96, 1, 1986, p. 82. 


\section{Deliberativismo como premissa nas entrevistas}

No primeiro artigo ${ }^{21}$, acusamos Silva de ter sutilmente induzido suas entrevistas com o fim de corroborar uma teoria política normativa, o deliberativismo, que o autor endossa em outro trabalho..$^{22}$ Silva afirma que essa acusação "não é precisa" ${ }^{23}$, já que o interesse com as perguntas era revelar as opiniões dos ministros sobre o papel do relator $n a$ deliberação.

De início, devemos reconhecer que nesse ponto nossa crítica pode ter sido um tanto especulativa. Contudo, esse ponto não é relevante para a tese do delegacionismo - não afeta qualquer das três condições para a sua validade. Convém esclarecer o que quisemos dizer com essa crítica.

Silva afirma que não fomos precisos ao afirmar que suas entrevistas foram induzidas por seu viés deliberativista. ${ }^{24}$ Falamos em viés deliberativista, ao invés de viés deliberativo, porque há uma diferença importante entre deliberativismo e deliberação. Entendemos por esse último o processo cognitivo que precede um julgamento. Isso vale para qualquer entidade com capacidade de julgar. Um indivíduo delibera e forma sua opinião sobre determinado assunto. Podemos dizer, por exemplo, que a ação de um indivíduo foi deliberada quando queremos significar que essa ação foi intencional.

Deliberação implica em discussão informada entre indivíduos quando o julgamento resultante é coletivo, enquanto que a noção de deliberativismo traz uma carga normativa de que a justificação pública dos mecanismos de decisão depende da sua capacidade de produzir julgamentos racionais, segundo algum critério de racionalidade.

Nossa abordagem é decididamente não-deliberativista, pois não estamos comprometidos com um modelo de decisão coletiva baseado no debate e na troca de informações entre os membros. Assumimos que procedimentos decisórios das cortes podem ser perfeitamente legítimos mesmo que não haja discussão entre os membros. Aliás, assumimos que

${ }^{21}$ ALMEIDA, Danilo dos Santos; BOGOSSIAN, Andre Martins. "Nos Termos do Voto do Relator": Considerações acerca da Fundamentação Coletiva nos Acórdãos do STF.

Revista Estudos Institucionais, Vol. 2, 1, 2016, p. 271-272.

${ }^{22}$ SILVA, Virgílio Afonso da. Deciding Without Deliberating. International Journal of Constitutional Law, Vol. 11, 3, 2013.

${ }_{23}^{3}$ SILVA, Virgílio. O Relator dá Voz ao STF? Uma réplica a Almeida e Bogossian.

Revista Estudos Institucionais, Vol. 2, 2, 2016, p. 652.

24 SILVA, Virgílio. O Relator dá Voz ao STF? Uma réplica a Almeida e Bogossian.

Revista Estudos Institucionais, Vol. 2, 2, 2016, p. 652. 
o STF adota uma estratégia assumidamente não-deliberativista para formar juízos coletivos fundamentados.

Contudo, isso não significa que não estamos tratando de deliberação. A posição deliberativista é de que o voto relator é o voto determinante na deliberação. Quando cada ministro reflete sobre um caso em seu gabinete, ele o faz com membro da corte, motivado pelo ethos desse grupo-agente. A falta de discussão entre os membros pode significar que o processo decisório não satisfaz as demandas de uma teoria deliberativista da decisão coletiva, mas não significa que as decisões não sejam deliberadas, ainda que essa deliberação se resuma a deferir ao relator o papel de decidir pela corte.

Apenas quisemos apontar essa distinção, bem como o compromisso do mesmo autor com teses normativas deliberativistas. ${ }^{25}$ Contudo, nada melhor que a posição do próprio autor sobre sua intenção ao escrever o texto.

\section{Ano de 2004 como ponto de inflexão (1 ${ }^{a}$ condição do delegacionismo)}

Silva apresenta uma série de objeções metodológicas à parte empírica do nosso artigo. Nosso interlocutor tem razão ao desconfiar dos dados apresentados, já que eles têm uma função importante no argumento oferecido. $\mathrm{O}$ uso da expressão deve ser caracterizado como uma prática habitual para que o delegacionismo faça sentido. Caso contrário, não podemos afirmar que os ministros têm a obrigação de esperar que ela seja utilizada em todos os acórdãos, mesmo antes de se iniciar o julgamento. Uma das condições do delegacionismo é que o uso da expressão seja uma prática dominante. $\mathrm{O}$ importante é que o ministro ingresse na sessão de julgamento sabendo que, ao final, constará do acórdão que a decisão foi tomada "nos termos do voto do relator". Como cada um deles sabe que esse é o caso, e como eles nunca se insurgem contra isso, então podemos assumir que eles, conjuntamente, aceitam o conteúdo dessa expressão.

Algumas críticas são justamente apresentadas por nosso interlocutor. Por exemplo, a de que não apresentamos naquele trabalho inicial

${ }_{25}^{5}$ SILVA, Virgílio. “Um Voto Qualquer"? O papel do ministro relator na deliberação no Supremo Tribunal Federal. Revista Estudos Institucionais, Vol. 1, 1, 2015, p. 184185.

3 JOURNAL OF INSTITUTIONAL STUDIES 2 (2017) 
potenciais explicações para o fenômeno. ${ }^{26}$ Não ignoramos que explicar tal comportamento seja importante para compreender seu significado. Porém, como ficará claro mais adiante, esse não é um problema decisivo. $\mathrm{O}$ argumento depende apenas do fato de que tal prática seja habitual (portanto previsível) no processo decisório da corte. Suas críticas mais contundentes, no entanto, dizem respeito à metodologia que adotamos para extrair nossos dados da ferramenta de busca do STF. O autor propõe uma série de alterações, e nós as acatamos integralmente.

Silva começa suas considerações afirmando que baseamos "uma parte importante de suas conclusões apenas nos resultados de uma pesquisa estritamente quantitativa das decisões plenárias do STF"27, presumivelmente referindo-se às nossas afirmações sobre a mudança brusca da prática da corte por volta da metade da década passada. Contudo, parte importante do nosso argumento, a razão pela qual a pesquisa quantitativa proposta é relevante e como ela deve ser interpretada, é a análise do conceito de agenciamento de grupo e como ele determina quais posições podemos razoavelmente atribuir à corte. Dedicamos ao tema dois tópicos (III e V) no artigo anterior ${ }^{28}$ e dois trabalhos posteriores. ${ }^{29} \mathrm{O}$ argumento baseia-se nas nossas posições relacionadas ao conceito de agenciamento de grupo. Por exemplo, afirmamos que o que constitui uma posição de grupo é somente o que é conjuntamente aceito por seus membros e que "isso exige que os membros expressem essa aceitação, subjetivamente, pensando e agindo como partes do grupo (em oposição a pensar e agir em satisfação a seus interesses pessoais) e, objetivamente, em concordância com as regras,

${ }^{26}$ SILVA, Virgílio. O Relator dá Voz ao STF? Uma réplica a Almeida e Bogossian.

Revista Estudos Institucionais, Vol. 2, 2, 2016, p. 655.

${ }^{27}$ SILVA, Virgílio. O Relator dá Voz ao STF? Uma réplica a Almeida e Bogossian.

Revista Estudos Institucionais, Vol. 2, 2, 2016, p. 653.

${ }^{28}$ ALMEIDA, Danilo dos Santos; BOGOSSIAN, Andre Martins. "Nos Termos do Voto do Relator": Considerações acerca da Fundamentação Coletiva nos Acórdãos do STF.

Revista Estudos Institucionais, Vol. 2, 1, 2016, p. 273-276/287-291.

${ }^{29}$ ALMEIDA, Danilo dos Santos. As Razões Ocultas do Supremo Tribunal Federal: um estudo sobre agenciamento de grupo na Corte. Tese (Doutorado em Teoria do Estado e Direito Constitucional), Pontifícia Universidade Católica do Rio de Janeiro, Rio de Janeiro, RJ, 2016; ALMEIDA, Danilo dos Santos. A Fundamentação de Decisões Judiciais Colegiadas e o Problema de sua Demarcação. In: Daniel Marchiori Neto; Danilo dos Santos Almeida (Orgs.). Estudos em Filosofia do Direito, Volume II: Ensaios em Filosofia do Direito. Rio Grande, RS: Editora FURG, 2017. 
práticas e valores constitutivos do grupo" ${ }^{30}$ Nossa pesquisa quantitativa serve para indicar a existência de uma dessas práticas constitutivas. $\mathrm{Ou}$ seja, o argumento é igualmente dependente de suas premissas conceituais e de suas premissas empíricas.

Em seguida, nosso interlocutor passa às considerações propriamente metodológicas. Segundo ele, a ferramenta de busca não é confiável: “os resultados que o sistema retorna nem sempre são um reflexo preciso do que ocorreu no julgamento, tampouco do que foi escrito na decisão final". ${ }^{31}$ Além de alguns acórdãos não serem disponibilizados ${ }^{32}$, em muitos dos acórdãos anteriores à 2004, o campo "decisão" - onde a expressão "nos termos do voto do relator" é registrada - não está indexado. ${ }^{33}$ Isso significa que, mesmo que essas decisões contivessem os termos de busca, elas não apareceriam como resultado, tornando-se falsos negativos do período anterior ao ponto de inflexão. Para evitar isso, seria necessário fazer a leitura do inteiro teor dos acórdãos pesquisado, o que Silva, com o auxílio de seu grupo, muito generosamente fez. ${ }^{34}$ Para simplificar a busca, ele distinguiu dois períodos: o primeiro inclui os anos de 2000 a 2004 e o segundo, de 2005 a 2009. ${ }^{35}$ Apenas as decisões do período 1 foram lidas.

A última importante consideração metodológica foi a revisão dos termos de busca que utilizamos. Silva demonstrou que as expressões que utilizamos não exclui decisões onde não se lê a expressão "nos termos do voto do relator", mas que contém "termos" e "relator" no mesmo parágrafo. Para evitar isso, Silva sugere a utilização dos termos de busca "nos adj1 termos adj1 do adj1 voto mesmo (relator ou relatora)" para pesquisar por acórdãos com a expressão. Para pesquisar acórdãos sem a expressão, ele recomenda subtrair o número de acórdãos com a expressão

${ }^{30}$ ALMEIDA, Danilo dos Santos; BOGOSSIAN, Andre Martins. "Nos Termos do Voto do Relator": Considerações acerca da Fundamentação Coletiva nos Acórdãos do STF.

Revista Estudos Institucionais, Vol. 2, 1, 2016, p. 277.

${ }^{31}$ SILVA, Virgílio. O Relator dá Voz ao STF? Uma réplica a Almeida e Bogossian.

Revista Estudos Institucionais, Vol. 2, 2, 2016, p. 655.

32 SILVA, Virgílio. O Relator dá Voz ao STF? Uma réplica a Almeida e Bogossian.

Revista Estudos Institucionais, Vol. 2, 2, 2016, p. 655, nota no 13.

${ }_{33}$ SILVA, Virgílio. O Relator dá Voz ao STF? Uma réplica a Almeida e Bogossian.

Revista Estudos Institucionais, Vol. 2, 2, 2016, p. 656.

${ }^{34}$ SILVA, Virgílio. O Relator dá Voz ao STF? Uma réplica a Almeida e Bogossian.

Revista Estudos Institucionais, Vol. 2, 2, 2016, p. 657.

35 SILVA, Virgílio. O Relator dá Voz ao STF? Uma réplica a Almeida e Bogossian.

Revista Estudos Institucionais, Vol. 2, 2, 2016, p. 656. 
do número total de decisões do período. ${ }^{36}$

Silva, então, apresenta os resultados de sua própria pesquisa baseada no paradigma alterado, que, segundo ele, o conduz a uma conclusão diferente da nossa. Ele afirma não ter encontrado aquilo que denominamos de ponto de inflexão na prática decisória do STF: um momento - o ano de $2004^{37}$ - em que os relatores dos acórdãos passam a incluir majoritariamente a expressão "nos termos do voto do relator". Segundo ele, "isso não significa, contudo, que não tenha havido um acréscimo relevante no uso da expressão. Significa, apenas, que o incremento foi menor e menos abrupto do que o imaginado inicialmente." 38

O surpreendente é que os dados que ele próprio coletou (tabelas 1 e 2) de forma alguma corroboram suas conclusões. A mudança do comportamento da corte foi, sim, abrupta; uma clara transformação no estilo de redação dos acórdãos. Curiosamente, nosso interlocutor não faz a comparação entre os períodos 1 e 2, o que seu argumento exigiria. Ele justamente corrige e critica nossa coleta de dados relativa ao primeiro período. A diferença entre o valor que obtemos $(9,28 \%)$ e o que ele obteve $(24,1 \%)$ é substancial. Porém, a diferença que realmente importa - aquela entre os períodos $1(24,1 \%)$ e $2(93,96 \%)$ - é muito maior e significativa, como veremos a seguir.

Tabela 1 - Comparativo entre os resultados de nossa pesquisa e os da pesquisa de Silva ${ }^{39}$, relativos ao período 1

\begin{tabular}{lcc}
\hline & Fichas STF & Inteiro teor \\
\hline Com a expressão “nos termos..." & $228(9,28 \%)$ & $592(24,10 \%)$ \\
\hline Sem a expressão “nos termos..." & $2229(90,72 \%)$ & $1847(75,17 \%)$ \\
\hline
\end{tabular}

${ }^{36}$ SILVA, Virgílio. O Relator dá Voz ao STF? Uma réplica a Almeida e Bogossian.

Revista Estudos Institucionais, Vol. 2, 2, 2016, p. 657, nota no 15.

${ }^{37}$ No primeiro artigo, identificamos erroneamente o ano de 2005 como este momento.

${ }^{38}$ SILVA, Virgílio. O Relator dá Voz ao STF? Uma réplica a Almeida e Bogossian.

Revista Estudos Institucionais, Vol. 2, 2, 2016, p. 658.

${ }^{9}$ SILVA, Virgílio. O Relator dá Voz ao STF? Uma réplica a Almeida e Bogossian.

Revista Estudos Institucionais, Vol. 2, 2, 2016, p. 658. 
Tabela 2 - Resultado da pesquisa de Silva ${ }^{40}$, relativos ao período 1, por anos

Uso da expressão "nos termos..." (dados corrigidos pela leitura dos acórdãos)

\begin{tabular}{lrrr} 
& Com a expressão & Sem a expressão & Acórdão não disponível \\
\hline $\mathbf{2 0 0 0}$ & $78(21,49 \%)$ & $283(77,96 \%)$ & $2(0,55 \%)$ \\
\hline $\mathbf{2 0 0 1}$ & $82(18,06 \%)$ & $364(80,18 \%)$ & $8(1,76 \%)$ \\
\hline $\mathbf{2 0 0 2}$ & $94(14,09 \%)$ & $567(85,01 \%)$ & $6(0,90 \%)$ \\
\hline $\mathbf{2 0 0 3}$ & $64(12,98 \%)$ & $428(86,82 \%)$ & $1(0,20 \%)$ \\
\hline $\mathbf{2 0 0 4}$ & $274(57,08 \%)$ & $205(42,71 \%)$ & $1(0,21 \%)$ \\
\hline
\end{tabular}

Total

592

1847

18

Refizemos a pesquisa respeitando as recomendações de Silva ${ }^{41}$ para o período 2 e os anos subsequentes, e comparamos nossos dados com os dele (tabela 3). Para facilitar a visualização, representamos os dados graficamente em valores absolutos (gráfico 1) e em valores percentuais (gráfico 2).

${ }^{40}$ SILVA, Virgílio. O Relator dá Voz ao STF? Uma réplica a Almeida e Bogossian.

Revista Estudos Institucionais, Vol. 2, 2, 2016, p. 658.

${ }^{41}$ Não fizemos a leitura dos acórdãos posteriores para verificar a presença do campo "decisão". Entendemos que isso não seria necessário, já que a ausência desse campo geraria apenas o risco de produzir falsos negativos (situações em que acórdãos contendo a expressão são reportados como se não tivessem). Como o uso da expressão entre os acórdãos do período 2 é predominante, o risco de falsos negativos não é um problema para o argumento. Também desconsideramos os acórdãos não disponíveis, por representarem um número insignificante. 
Tabela 3 - Dados completos para os períodos 1 e 2, e anos subsequentes, por anos

\begin{tabular}{rrrr}
\hline & Período & com a expressão & sem a expressão \\
\hline \multirow{3}{*}{ Período 1 } & 2000 & $78(21,61 \%)$ & $283(78,39 \%)$ \\
& 2001 & $82(18,38 \%)$ & $364(81,61 \%)$ \\
& 2002 & $94(14,22 \%)$ & $567(85,78 \%)$ \\
& 2003 & $64(13,01 \%)$ & $428(86,99 \%)$ \\
Período 2 & $274(57,20 \%)$ & $205(42,8 \%)$ \\
\hline 2004 & $334(82,47 \%)$ & $71(17,53 \%)$ \\
& 2005 & $428(88,43 \%)$ & $56(11,57 \%)$ \\
& 2006 & $905(93,39 \%)$ & $64(6,60 \%)$ \\
Anos subsequentes & $1016(94,69 \%)$ & $57(5,31 \%)$ \\
& 2008 & $494(87,28 \%)$ & $72(12,72 \%)$ \\
\hline 2009 & $643(93,46 \%)$ & $45(6,54 \%)$ \\
& 2010 & $611(92,86 \%)$ & $47(7,14 \%)$ \\
& 2011 & $259(92,83 \%)$ & $20(7,17 \%)$ \\
& 2012 & $620(90,78 \%)$ & $63(9,22 \%)$ \\
& 2013 & $710(92,09 \%)$ & $61(7,91 \%)$ \\
& 2014 & $545(93,16 \%)$ & $40(6,84 \%)$ \\
& 2015 & $556(95,04 \%)$ & $29(4,96 \%)$ \\
\hline
\end{tabular}

Gráfico 1 - Gráfico com os dados completos, em valores absolutos

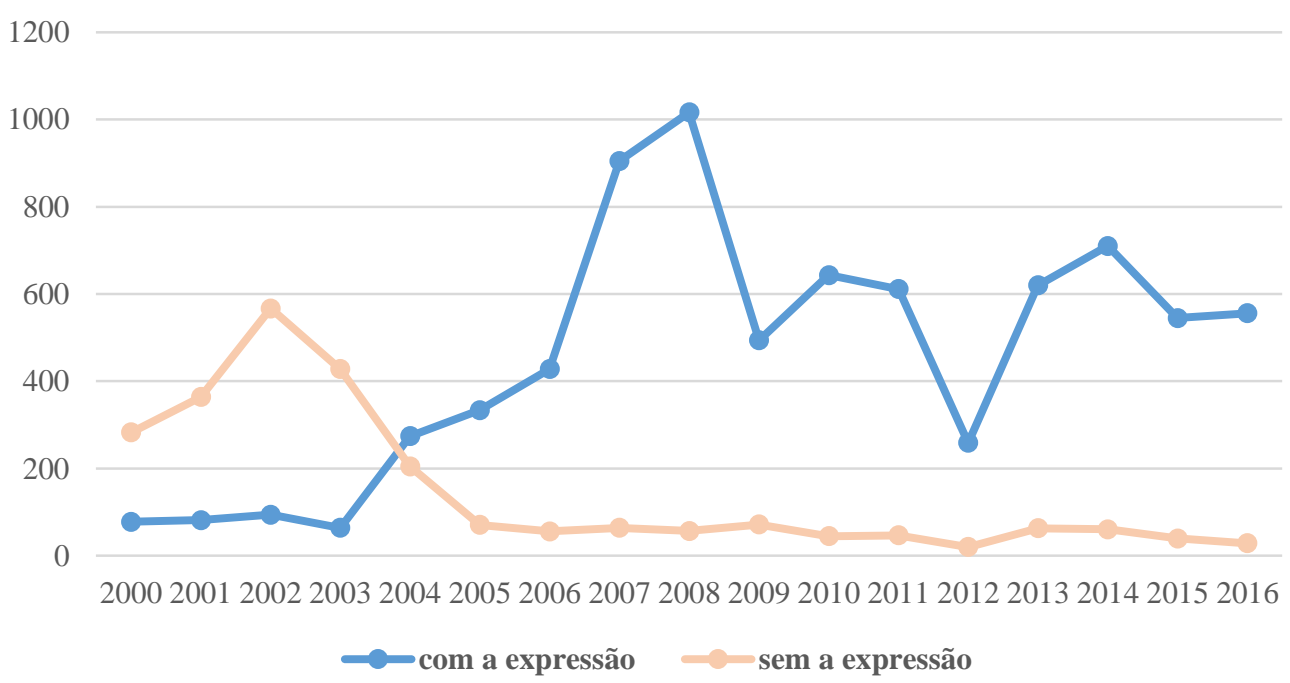

3 JOURNAL OF INSTITUTIONAL STUDIES 2 (2017) 
Gráfico 2 - Gráfico com os dados completos, em valores percentuais

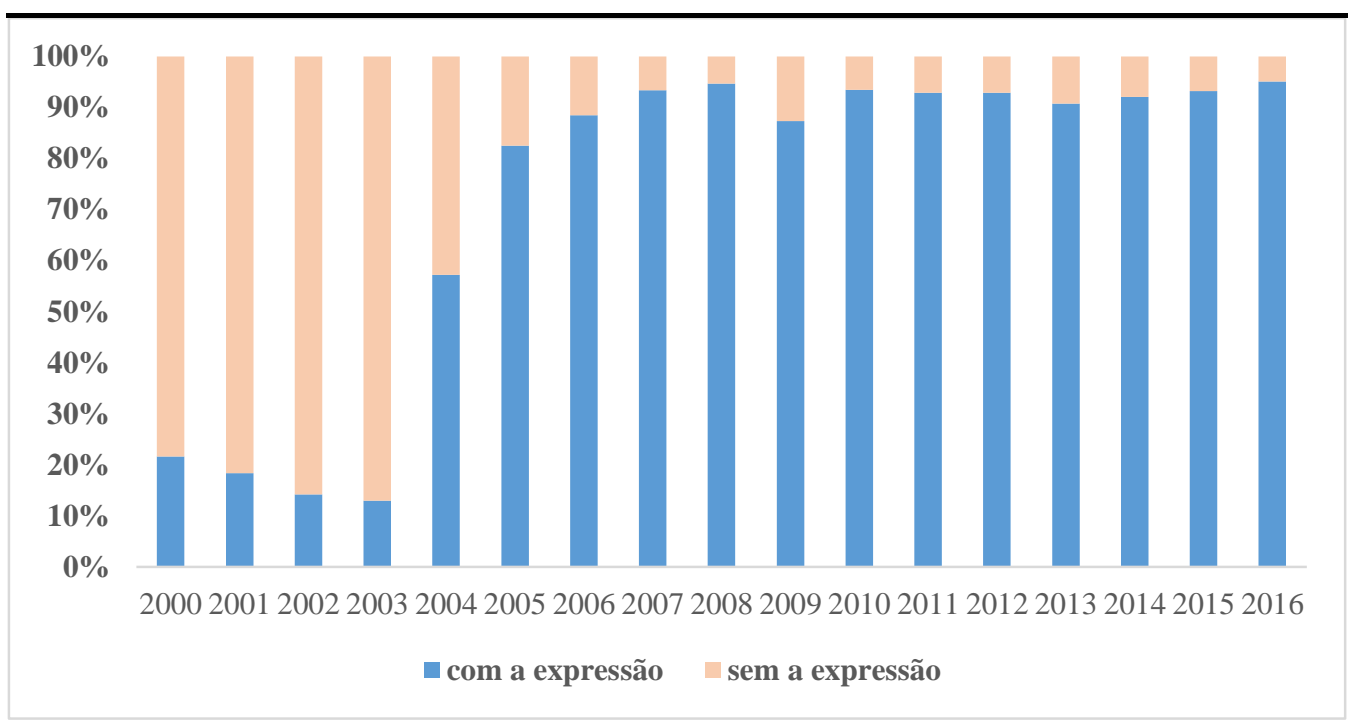

Vemos que há uma mudança importante em 2004. Sem os dados do período 2 , não é possível saber se ela reflete uma mudança consistente ou apenas uma flutuação insignificante. Para indicar que "não há uma tendência constante no uso da expressão", Silva chega a apontar que houve decréscimo entre 2000 e $2003 .{ }^{42}$ Quando completamos a tabela com os dados para o período 2, utilizando a metodologia proposta por Silva, verificamos que a diferença entre o ano de 2004 e os anos anteriores não foi uma mera flutuação, mas o início de uma mudança drástica no processo decisório da corte.

Em conclusão, mesmo com as correções metodológicas propostas por Silva, que acolhemos sem reservas, nossas observações originais parecem suficientemente sustentadas: (i) atualmente, o uso da expressão está presente na quase totalidade dos acórdãos; e (ii) essa prática tornou-se dominante após uma mudança drástica na técnica de redação dos acórdãos. Suas considerações melhoraram sensivelmente a precisão do nosso paradigma. A replicação que o autor e seu grupo de pesquisa generosamente realizaram identificou um número muito maior de acórdãos contendo a expressão no período 1 . Porém, ao restringirem a busca às decisões até 2004, não lhes foi possível avaliar a existência do ponto de inflexão.

${ }^{2}$ SILVA, Virgílio. O Relator dá Voz ao STF? Uma réplica a Almeida e Bogossian.

Revista Estudos Institucionais, Vol. 2, 2, 2016, p. 659. 
Como reconhece Silva ${ }^{43}$, é importante não perder de vista que a premissa do argumento delegacionista não depende da existência de uma mudança tão brusca no entendimento. Na verdade, a conclusão relevante do estudo empírico é a primeira (i), pois é ela que indica que o uso da expressão pelo relator é previsível da perspectiva de um ministro que está formulando seu voto. A segunda conclusão (ii) - que foi rejeitada por Silva, mas que ainda acreditamos suportada pelas evidências - serve apenas para indicar que a prática é intencional ou, pelo menos, consciente. Sustentar que a prática foi estabelecida intencionalmente é uma forma de argumentar por sua previsibilidade, mas não é a única. Veremos agora que esse ponto não é indispensável ao argumento.

\section{Significado da expressão ( $2^{\mathrm{a}}$ condição do delegacionismo)}

Dissemos no primeiro artigo e confirmamos acima que a mudança drástica indica mudança de intenção. Talvez tenha faltado esclarecer que, por mudança de intenção, estamos fazendo uma alegação normativa, e não empírica. Pode-se discutir o que se passa pela cabeça dos ministros ${ }^{44}$ ao aderir ao uso da expressão. Mas seria ingênuo achar que as palavras dos acórdãos representam fielmente suas verdadeiras intenções.

Para ilustrar esse ponto, cooptaremos o exemplo oferecido por nosso interlocutor. Para argumentar que existem expressões usadas apenas por força de hábito e que não devem ser levadas tão a sério quanto pretendemos, ele menciona a expressão "ausente, justificadamente, o ministro x", que frequentemente aparece nos acórdãos. O autor tem razão em apontar a vagueza da expressão. Afinal,

Qual é o sentido da palavra "justificadamente"? Há ausências injustificadas? Caso não existam, a palavra "justificadamente" é supérflua. Mas se há ausências que podem ser consideradas injustificadas, quais são elas? São as ausências para as quais o ministro ou a ministra não deu nenhuma justificação, qualquer que seja? ${ }^{45}$

Porém, apesar do uso formular da expressão e de claramente não ter

${ }^{43}$ SILVA, Virgílio. O Relator dá Voz ao STF? Uma réplica a Almeida e Bogossian.

Revista Estudos Institucionais, Vol. 2, 2, 2016, p. 659.

${ }^{44} \mathrm{Ou}$, ainda, aos seus assessores, já que há uma divisão de trabalhos em cada banca.

45 SILVA, Virgílio. O Relator dá Voz ao STF? Uma réplica a Almeida e Bogossian.

Revista Estudos Institucionais, Vol. 2, 2, 2016, p. 663. 
qualquer propósito explicativo, ela tem uma função normativa muito clara e bastante relevante: ela preserva o ministro faltante de potenciais críticas. Quando essa expressão consta do acórdão, pouco importa se efetivamente houve, por parte do ministro ausente, o ato de se justificar perante os demais. O que a corte afirma com essa expressão é que o ministro não pode ser responsabilizado - política ou moralmente, já que não cabe falar em responsabilidade jurídica - por ter faltado àquela sessão. Com isso, a corte não está propriamente dizendo algo, mas sim fazendo algo: eximindo o faltante. Uma ausência em um julgamento pode ser vista como algo que compromete a legitimidade da decisão, principalmente pela parte vencida. É natural que uma corte queira se proteger contra eventuais críticas ao seu processo decisório, e o "justificadamente" parece estar cumprindo exatamente essa função. Concordamos que a expressão "ausente, justificadamente..." deve ter um impacto prático mínimo, mas isso não significa que sejam "palavras inúteis".

Outro exemplo de palavras inúteis em documentos oficiais que o autor oferece é a determinação, estabelecida no art. $77, \S 3^{\mathbf{o}}$ da Constituição Federal, de que o segundo turno das eleições presidenciais ocorra "em até vinte dias após a proclamação do resultado". Essa determinação seria inútil porque já existe data fixa para tanto no caput do mesmo artigo. ${ }^{46} \mathrm{O}$ exemplo é inócuo como crítica à alegação delegacionista. Ele indica uma situação em que uma norma é tornada inaplicável por consequência lógica de outra norma. Evidentemente, esse não é o caso da expressão "nos termos do voto do relator", já que, aqui, o problema é justamente a ausência de outro indicativo claro de como devemos localizar os fundamentos do voto do relator - é o que denominamos de problema da demarcação. ${ }^{47}$

Uma refutação do delegacionismo não deve demonstrar que a expressão é não praticamente inútil, mas juridicamente inerte. Ou seja, precisa demonstrar que nenhuma obrigação jurídica decorre da sua presença em um texto oficial. No exemplo eleitoral, não há qualquer indício de que a expressão seja juridicamente inerte. Imaginemos que a determinação de que o segundo turno ocorra no último domingo de outubro seja revogada. Naturalmente, a expressão "em até vinte dias

${ }^{46}$ SILVA, Virgílio. O Relator dá Voz ao STF? Uma réplica a Almeida e Bogossian.

Revista Estudos Institucionais, Vol. 2, 2, 2016, p., nota no 25.

${ }^{47}$ ALMEIDA, Danilo dos Santos. A Fundamentação de Decisões Judiciais Colegiadas e o Problema de sua Demarcação. In: Daniel Marchiori Neto; Danilo dos Santos Almeida (Orgs.). Estudos em Filosofia do Direito, Volume II: Ensaios em Filosofia do Direito. Rio Grande, RS: Editora FURG, 2017.

3 JOURNAL OF INSTITUTIONAL STUDIES 2 (2017) 
após a proclamação do resultado" deixa de ser praticamente inútil e torna-se automaticamente a regra a ser observada, como geralmente é o caso com manifestações oficiais de uma autoridade competente.

Voltemos à expressão "nos termos do voto do relator". Essa fórmula tem sido tão frequentemente repetida que não é razoável supor que o ministro-relator tome uma decisão consciente ao incluí-la. Podemos imaginar um arquivo de texto que sirva de modelo para acórdãos, já contendo essa e outras expressões recorrentes. Dessa forma, o fato de ela constar das decisões explica muito pouco dos processos psicológicos envolvidos no processo decisório. Mas isso não diz nada sobre seus aspectos normativos. Admitindo-se que a melhor interpretação seja a de que os fundamentos sugeridos pelo relator são os fundamentos aderidos conjuntamente pelos ministros - ou seja, admitindo-se sua interpretação literal - e verificadas as outras condições que mencionamos acima como premissas do argumento delegacionista, então sua presença constitui um compromisso de cada ministro com os demais no sentido de formar uma decisão, ao mesmo tempo, coletiva e consistente - tarefa muito mais difícil do que às vezes reconhecemos quando os membros da corte precisam contar apenas com seu poder de persuasão.

Há um problema de ônus da prova nessa discussão. Se uma expressão consta de um documento oficial, devemos assumir que ela significa exatamente $o$ que diz, enquanto parte desse documento oficial. Analogamente, é como se eximíssemos alguém de respeitar as letras (não tão) miúdas de um contrato que assinou, apenas porque essa pessoa provavelmente não queria ter endossado uma determinada cláusula caso a conhecesse. A natureza normativa de um contrato faz com que ele seja, geralmente ${ }^{48}$, do ponto de vista jurídico, irrelevante como guia para a vontade empírica das partes. Sua função principal é comprovar um compromisso assumido pelas partes entre si. Até que seja apontado algum vício em sua constituição, em geral, vale o que está escrito, não importa se o compromisso tenha sido assumido "por força do hábito" 49 ou outra motivação subjetiva.

Parece-nos que a mesma lógica vale para os acórdãos. A força normativa de cada parte do acórdão deve ser presumida, salvo se tivermos razões - jurídicas, políticas ou de outra natureza - para não a reconhecer. Não nos parece que Silva tenha apresentado razões para

${ }^{48}$ Naturalmente, sabemos haver exceções a essa regra. O que importa é apontar como atos linguísticos no direito, quando seguem as formalidades relevantes, produzem efeitos jurídicos.

49 SILVA, Virgílio. O Relator dá Voz ao STF? Uma réplica a Almeida e Bogossian.

Revista Estudos Institucionais, Vol. 2, 2, 2016, p. 660. 
tanto.

\section{Quantas cortes cabem no STF? A importância da distinção entre casos mais ou menos importantes no STF}

Silva pretende distinguir casos mais importantes dos menos importantes. "Casos mais importantes" é definido como aqueles que "fazem parte do cotidiano de todos os tribunais constitucionais", ou seja, quando se trata do "papel do Supremo Tribunal Federal como corte constitucional". ${ }^{50}$ A distinção seria importante porque, segundo ele, o delegacionismo daria um "peso insustentável" ao voto do relator nos casos mais importantes. Neles, há uma tendência de os ministros expressarem novos argumentos em seus votos. O delegacionismo tornaria "quase inúteis" os demais votos, já que as razões presentes no voto do relator são escritas individualmente e antes da sessão de julgamento. ${ }^{51}$

Nosso contra-argumento é de que a distinção entre casos fáceis e difíceis é de conteúdo, não de forma. O argumento delegacionista é procedimental: o voto do relator carrega os fundamentos coletivos por causa de uma regra tácita do processo decisório da corte, não importa o caso. É preciso lembrar que a tese delegacionista é uma tentativa de solução do problema da demarcação (a falta de parâmetros gerais para identificar os fundamentos coletivos dos casos, em oposição aos fundamentos individuais dos ministros), e enquanto tal indica uma questão formal do processo decisório. Assim, se o problema aflige igualmente casos fáceis e difíceis, a tese delegacionista também atingiria todos os casos. E é por isso que a proporção de decisões contendo a fórmula em relação ao total de casos decididos é tão grande. $\mathrm{O}$ uso da fórmula é uma etapa do processo cognitivo da corte-agente para se comunicar com as partes do processo e com o público em geral. A partir de 2004, podemos dizer que a corte tornou essa etapa parte do processo decisório geral, independentemente das peculiaridades do caso decidido.

Discordamos que haja uma diferença relevante no protocolo que

${ }^{50}$ SILVA, Virgílio. “Um Voto Qualquer"? O papel do ministro relator na deliberação no Supremo Tribunal Federal. Revista Estudos Institucionais, Vol. 1, 1, 2015, p. 187188; e SILVA, Virgílio. O Relator dá Voz ao STF? Uma réplica a Almeida e Bogossian. Revista Estudos Institucionais, Vol. 2, 2, 2016, p. 665.

${ }^{51}$ SILVA, Virgílio. O Relator dá Voz ao STF? Uma réplica a Almeida e Bogossian.

Revista Estudos Institucionais, Vol. 2, 2, 2016, p. 664. 
regula processamento de informações nos ditos casos mais importantes, em comparação com os menos importantes. O problema não é propriamente o uso da distinção para descrever a atividade do relator, mas não ter levado em consideração funções da relatoria que perpassam a distinção. A corte, como qualquer órgão colegiado, conta com uma série de protocolos para orientar a coordenação de seus membros. Afirmamos que Silva não deveria "extrapolar [suas conclusões] das características nas quais a diferença é observável para as características onde ela não foi observada" e que "É necessário um argumento adicional demonstrando ou que há evidências empíricas que esse é o caso, ou que a dicotomia se impõe por força de outras considerações normativas", e cremos que Silva não as apresentou.

De todo modo, como afirmamos anteriormente ${ }^{52}$, ainda que essa distinção entre casos baseada numa avaliação subjetiva da relevância ou impacto social seja útil para alguns propósitos, sua importância não pode ser exagerada. O que é mais importante: ela não pode ser assumida.

Por isso, elaboramos uma lista ${ }^{53}$ de casos que interpretamos como importantes e fizemos um levantamento do uso da fórmula em seus acórdãos. O objetivo é simples: comparar a frequência do uso da fórmula entre casos importantes e casos corriqueiros. Caso não haja diferença, então a interpretação delegacionista é relevante também para esses casos.

Não há um conceito único ou sequer critérios universalmente reconhecidos na doutrina jurídica de quais elementos de um caso permitem chamá-lo de "difícil", de modo que fosse possível fazer uma coleta direta dos casos difíceis a partir das características de cada caso no portal do STF. O próprio autor, antes de oferecer sua crítica, reconhece que a distinção "baseia-se mais na intuição do que em critérios objetivos".$^{54}$ Assim, em nossa tréplica optamos por utilizar como critério o reconhecimento por autores consagrados no direito constitucional brasileiro de que certos casos são considerados difíceis. Esse método, reconhecemos, é potencialmente sub e sobreinclusivo: é possível que outros casos, ausentes de nossa lista, possam ser considerados como difíceis, do mesmo modo como é possível apresentar críticas pontuais a um ou outro caso, que poderia ou não ser considerado difícil.

52 ALMEIDA, Danilo dos Santos; BOGOSSIAN, Andre Martins. "Nos Termos do Voto do Relator": Considerações acerca da Fundamentação Coletiva nos Acórdãos do STF.

Revista Estudos Institucionais, Vol. 2, 1, 2016, p. 270

${ }^{53}$ Disponível com os autores.

${ }^{54}$ SILVA, Virgílio. O Relator dá Voz ao STF? Uma réplica a Almeida e Bogossian.

Revista Estudos Institucionais, Vol. 2, 2, 2016, p. 666. 
Deste modo, utilizamos artigos acadêmicos ${ }^{55}$ a retrospectiva anual elaborada pelo Ministro Luis Roberto Barroso ${ }^{56}$ dos casos mais relevantes - ainda que, reiteramos, possa não haver uma equivalência absoluta entre o conceito de casos difíceis e o critério de relevância utilizado pelo próprio Ministro para apresentar os casos em sua retrospectiva.

De um total de 200 casos, entre 2004 e 2016, foram excluídos 48 registros seja pelo caso ainda estar em julgamento, pelo fato de que o acórdão ainda não foi publicado, por tratarem de decisões monocráticas, ou por outro motivo que impossibilitou o acesso ao inteiro teor do acórdão. Dos 152 casos restantes, em 101 (66,5 \%) a fórmula foi utilizada, enquanto que em 51 (33,5\%) ela não foi, o que representa uma proporção significativa, ainda que inferior à verificada na totalidade de casos, quando desconsiderada a questão da natureza do caso.

Isso indica que, ainda que possa ser um fator que de algum modo interfira no processo decisório, a afirmação de Silva de que o delegacionismo é "incompatível com a prática decisória recente do tribunal, ao menos nos casos mais importantes, nos quais ministros e ministras levam para a sessão de julgamento seus votos, longos e

${ }_{55}$ SILVA, Virgílio. “Um Voto Qualquer"? O papel do ministro relator na deliberação no Supremo Tribunal Federal. Revista Estudos Institucionais, Vol. 1, 1, 2015; BARROSO, Luís Roberto. Supremo Tribunal Federal, Direitos Fundamentais e Casos Difíceis. Revista Brasileira de Direito Constitucional - RBDC, No. 19, 2012; e CAMPOS, Carlos Alexandre de Azevedo. Explicando o Avanço do Ativismo Judicial do Supremo Tribunal Federal. Revista do Instituto do Direito Brasileiro - RIDB, Vol. 2, 8, 2013.

${ }_{56}$ Cf. Disponível em: <http://www.conjur.com.br/2017-jan-05/10-julgamentosimportantes-stf-ano-segundo-barroso $>;<$ http://www.conjur.com.br/2015-dez28/retrospectiva-2015-10-principais-decisoes-pauta-supremo $>$ $<$ http://www.conjur.com.br/2014-dez-31/retrospectiva-2014os-10-julgamentosimportantes-supremo $>;<$ http://www.conjur.com.br/2013-dez-26/retrospectiva-2013-11julgamentos-marcaram-ano-stf $>$; $<$ http://www.conjur.com.br/2013-dez26/retrospectiva-2013-ruas-opiniao-publica-constituicao-supremo>; $<$ http://www.conjur.com.br/2013-jan-03/retrospectiva-2012-stf-entre-papeiscontramajoritario-representativo $>$; $<$ http://www.conjur.com.br/2012-jan03/retrospectiva-2011-stf-foi-permeavel-opiniao-publica-subserviente>; $<$ http://www.conjur.com.br/2010-dez-28/retrospectiva-2010-prudencias-ousadiasmudancas-necessarias-stf $>;<$ http://www.conjur.com.br/2009-dez-15/retrospectiva2009-ativismo-judicial-mobiliza-justica-sociedade $>$; $<$ http://www.conjur.com.br/2008dez-22/judicializacao ativismo legitimidade democratica>;

$<$ http://www.conjur.com.br/2007-dez$\underline{13 / a t u a c a o ~ s t f ~ r e d e f i n i u ~ r e l a c o e s ~ e n t r e ~ p o d e r e s ~}>$. Acesso em: 22 de fevereiro de 2018. 
detalhados, já escritos" não nos parece acertada.

\section{CONCLUSÃO}

Por fim, queremos novamente destacar - e agradecer - o cuidado e precisão como Silva se debruçou sobre nosso trabalho e ofereceu diversos comentários extremamente pertinentes, principalmente quanto ao método de pesquisa que havíamos empregado anteriormente. Procuramos aqui contextualizar o pano de fundo teórico no qual se insere a tese delegacionista, na busca por chaves interpretativas que lidem com o problema de demarcação visto no Supremo Tribunal Federal - como identificar os fundamentos coletivos das decisões do STF como grupoagente, e como diferenciá-los dos fundamentos individuais de cada ministro.

Cremos, contudo, que o argumento delegacionista sobrevive: dando os créditos às críticas metodológicas oferecidas por Silva como feito nesta tréplica, entendemos que as contrarrazões teóricas e evidências empíricas que ora apresentamos mostram que o argumento permanece sólido.

O delegacionismo permanece de pé mesmo reconhecendo, como fizemos na seção 2 desta tréplica, que talvez ele não seja a chave que melhor interprete a prática do Supremo. Assim, poderíamos até admitir que ainda que não tenha qualquer implicação prática, o delegacionismo se impõe como interpretação válida dos compromissos que os ministros efetivamente assumem perante o colegiado.

Mas se o delegacionismo não é a melhor resposta para a definição de critérios para as decisões coletivas, então qual é? Seria uma interpretação agregativista, calcada na ideia de que as atitudes de um grupo são formadas pela agregação das atitudes individuais relevantes de seus membros? Ou ainda uma postura negacionista, que sugere que simplesmente não há fundamentação coletiva das decisões da corte? Pretendemos que os próximos capítulos deste debate ajudem a responder essas perguntas. 


\section{REFERÊNCIAS}

ALMEIDA, Danilo dos Santos. As Razões Ocultas do Supremo Tribunal Federal: um estudo sobre agenciamento de grupo na Corte. Tese (Doutorado em Teoria do Estado e Direito Constitucional), Pontifícia Universidade Católica do Rio de Janeiro, Rio de Janeiro, RJ, 2016.

. A Fundamentação de Decisões Judiciais Colegiadas e o Problema de sua Demarcação. In: Daniel Marchiori Neto; Danilo dos Santos Almeida (Orgs.). Estudos em Filosofia do Direito, Volume II: Ensaios em Filosofia do Direito. Rio Grande, RS: Editora FURG, 2017.

ALMEIDA, Danilo dos Santos; BOGOSSIAN, Andre Martins. “Nos Termos do Voto do Relator": Considerações acerca da Fundamentação Coletiva nos Acórdãos do STF. Revista Estudos Institucionais, Vol. 2, 1, 2016.

BARROSO, Luís Roberto. Supremo Tribunal Federal, Direitos Fundamentais e Casos Difíceis. Revista Brasileira de Direito Constitucional - RBDC, No. 19, 2012.

BOGOSSIAN, Andre Martins; ALMEIDA, Danilo dos Santos. É Possível Falar em Precedente "do Supremo"? In: Joaquim Falcão; Diego Werneck Arguelhes; Felipe Recondo (Orgs.). Onze Supremos: o Supremo em 2016. Belo Horizonte, MG: Letramento, 2017.

CAMPOS, Carlos Alexandre de Azevedo. Explicando o Avanço do Ativismo Judicial do Supremo Tribunal Federal. Revista do Instituto do Direito Brasileiro - RIDB, Vol. 2, 8, 2013.

KORNHAUSER, Lewis; SAGER, Lawrence. Unpacking the Court. The Yale Law Journal, Vol. 96, 1, 1986. 
LEITE, Fábio Carvalho; BRANDO, Marcelo Santini. Dispersão de Fundamentos no Supremo Tribunal Federal. Direito, Estado e Sociedade, No. 48, 2016.

MENDES, Conrado. Projeto de uma Corte Deliberativa. In: Adriana Vojvodic, et. al.. (Orgs.). Jurisdição Constitucional no Brasil. São Paulo, SP: Malheiros, 2012.

SILVA, Virgílio Afonso da. Deciding Without Deliberating. International Journal of Constitutional Law, Vol. 11, 3, 2013.

. "Um Voto Qualquer"? O papel do ministro relator na deliberação no Supremo Tribunal Federal. Revista Estudos Institucionais, Vol. 1, 1, 2015.

. O Relator dá Voz ao STF? Uma réplica a Almeida e Bogossian. Revista Estudos Institucionais, Vol. 2, 2, 2016.

TUOMELA, Raimo. Social Ontology: collective intentionality and group agents. New York, NY: Oxford University Press, 2013.

O Delegacionismo no STF: uma tréplica a Virgílio Afonso da Silva The Delegation Thesis in the Brazilian Supreme Court: a rejoinder to Virgílio Afonso da Silva Submetido em: 2017-05-16 Aceito em: 2017-11-30 